\title{
DELIVERY AND PICK-UP PROBLEM TRANSPORTATION - MILK RUN OR CONVENTIONAL SYSTEMS
}

\author{
Delmo Alves de Moura \\ Federal University of $A B C$, Brazil \\ E-mail: delmo.moura@ufabc.edu.br \\ Rui Carlos Botter \\ University of São Paulo, Brazil \\ E-mail: rcbotter@usp.br \\ Submission: 05/02/2016 \\ Revision: 22/02/2016 \\ Accept: 28/02/2016
}

\section{ABSTRACT}

This paper examines the role of inventory and transportation in the supply system of parts adopted by most of the Brazilian automotive companies to feed their assembly lines. It is a system for programmed collection of pieces called Milk Run that aims, within a window of time, to collect parts from suppliers, fulfilling established routes in order to minimize the cost of transport operations and reducing inventory in the supply chain. Milk Run, a scheduled collection system of parts can be carried out by automotive industry itself: the automaker manage the best route for its collector vehicle, determining the quantity of parts required to collect at each supplier within a given route, aiming to best utilize the capacity of the vehicle. Another way to work within the Milk Run system is the automaker to find the best routing and determines the amount of parts needed to be collected from each supplier on each trip. The collection, however, is held by a third carrier. As a third way of working, the assembler can determine the quantity of parts to collect and when it will require them. A logistics carrier determines the best routing for the collection of pieces in order to meet the production plan so that there is not a lack of parts or components on the assembly line, which would lead to a stop. In this case, the logistics carrier transports parts on its own fleet of vehicles or transfer the transport operation to a carrier. 
DOI: 10.14807/ijmp.v7i3.434

Keywords: Milk Run Systems, Lot Size, Transportation Problem.

\section{INTRODUCTION}

Many companies use the Milk Run system in Brazilian automobiles industries. The core of this process is to minimize the inventory (holding) and transportation cost. The cost of procurement parts is very relevant in the total cost of a company like automobile industry (WHITE; CENSLIVE, 2013; RAHMAN; WU, 2011).

Figure 1 depicts the scheme of the Milk Run System. The truck sets off to collect the parts from its suppliers and to leave empty containers for the next collection. Obeying a time window, it returns to the automaker, bringing a load corresponding to $85 \%$ of its weight or cubic volume, to minimize transport costs (GORMAN et. al., 2014; DEMIR; WOENSEL; KOK, 2014).

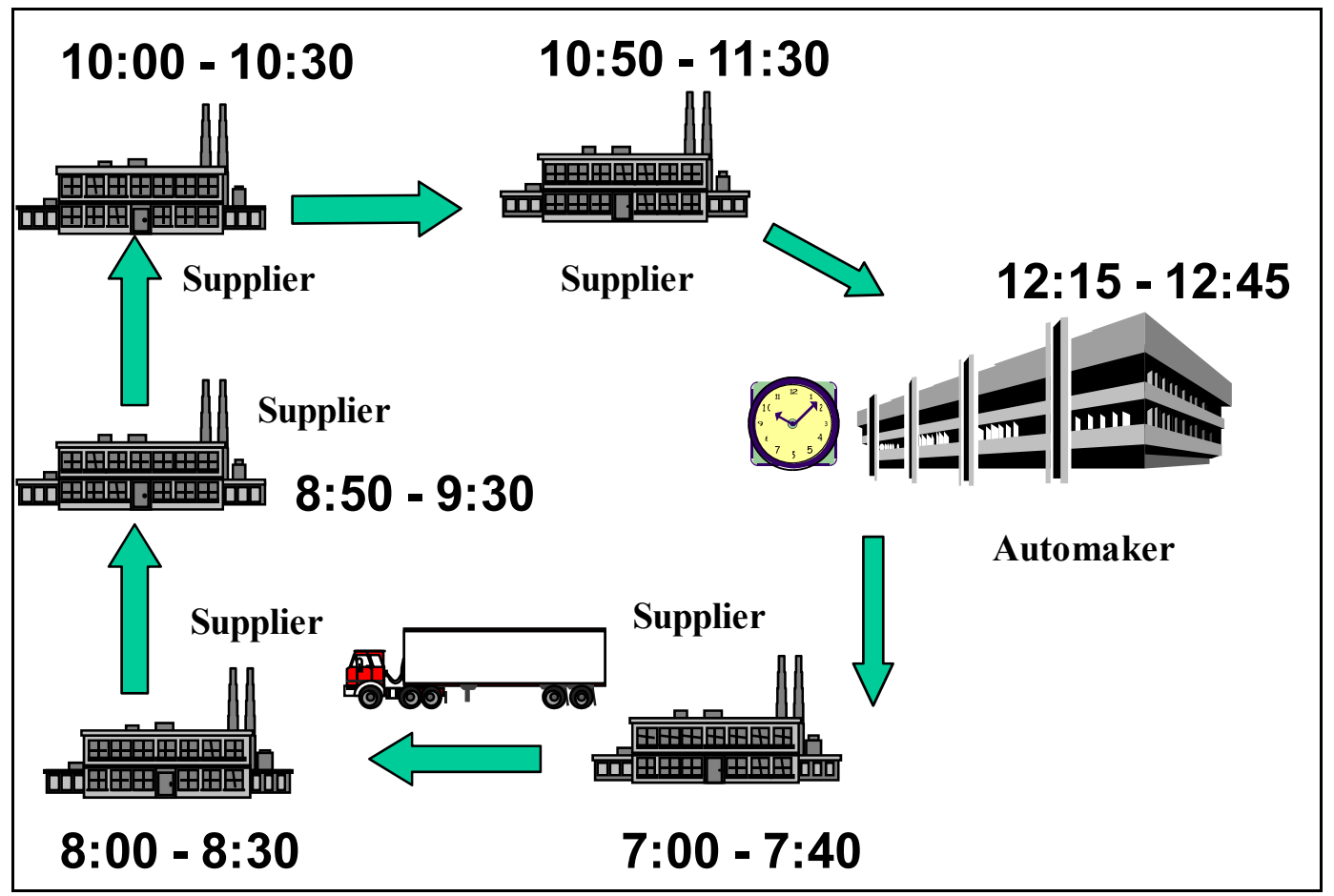

Figure 1 - Schedule collection System, Milk Run

For this system, it is necessary great integration between all elements like automotive company, supplier companies and logistic carrier. The correct and quick flow of information about the necessity of automotive parts is essential to the success of the system. If an automotive company has difficulty to measure its demand, it is unlikely to have a lean process in the Milk Run system (ZOTTERI, 2013; FUENTES; DÍAZ; JURADO, 2012; WIENGARTEN et al., 2013; BENNET; KLUG, 2012). 
DOI: 10.14807/ijmp.v7i3.434

The advantage of Milk Run system is that it is a just in time process because parts can be delivered to the automotive company plant many times a day. The Just in Time system requires quality in information between automotive, logistic carrier and suppliers, quality parts to supply the automotive plant and accurate quantity of parts in the correct container, at exact time that the automotive company needs them. The fundamental elements utilized in just-in-time system are also needed in Milk Run system (FUENTES; DÍAZ; JURADO, 2012; WIENGARTEN et al., 2013; BENNET; KLUG, 2012; IVER; SARANGA; SESHADRI, 2013).

In Conventional system of procurement, the supplier transports the parts to the automotive plant while in the Milk Run system the automotive uses one logistic carrier to collect the parts in the plant of each supplier onto its collecting route.

\section{THE ROLE OF THE ACTORS}

The automotive company must inform all suppliers its demand for parts. It must define the kind of container it will use in that system. Thus, all containers will have a standard and consequently the control of the parts transported between suppliers and automotive plant will improve (ZOTTERI, 2013; FUENTES; DÍAZ; JURADO, 2012).

The automotive company must unload the vehicle used to collect the pieces with time windows (Milk Run) when it is in their factory, avoiding waste of time in that operation. It must provide empty containers to return them to the suppliers. It must load the vehicle used in the Milk Run system with the empty containers in at the correct time window. If the automotive plant requires some parts beyond that it was initially planned in its master production schedule, it must notify the supplier about that change in the quantity desired in apt time or pay premium freight to that new necessity (SUN et al., 2014; FUENTES; DÍAZ; JURADO, 2012).

The logistic carrier must receive the master production schedule from the automotive company and define the transportation of the parts according to the demand of the automotive plant. It is responsible for programming the route of the vehicle minimizing the cost of the transportation in the collecting operation. The vehicle that is used in this operation must have $85 \%$ of its capacity (weight or volume) occupied. The vehicle can visit a supplier more than once a day. It depends on the demand of the automotive company plant because the main target is to 
minimize the inventory in the supply chain process. When the logistic carrier collects parts it must take the empty containers to the next collect. The logistic carrier must check all the parts (quantity and containers) at each collecting operation. The supplier must plan the empty containers three days before the collecting and confirm its necessity to the logistic carrier. The supplier must load the logistic carrier's vehicle only with the parts required by the automotive company. More parts than the quantity the automotive ordered might increase transportation cost (freight) and inventory cost (holding cost). All the parts must be in the same containers that the automotive company defined. The document must be ready when the vehicle of collecting arrives in the supplier's plant (GUIMARÃES et al., 2014; ZOTTERI, 2013; HA; PARK; CHO, 2011; FUENTES; DÍAZ; JURADO, 2012; TING; LIAO, 2013; WHITE; CENSLIVE; 2013; RAHMAN; WU, 2011).

A scheduled collection system of parts aims to minimizing freight cost using the full capacity of the transport vehicle (volume or weight), with the best routing for collection of parts from suppliers, maximizing inventory turnover and discipline the supplier, increasing the frequency of supply, feeding the automaker just with the parts in the quantities ordered, within required time and standard packaging and reducing the number of vehicles in the automaker and improving coordination of these vehicles at the factory. As the pieces are collected in each supplier, there is a reduction of the number of vehicles to perform the supply. As each vehicle has a preset schedule for delivery of materials collected, there is better control of unloading of parts (WANG; CHEN, 2013; SNOO; WEZEL; WORTMANN, 2011; FUENTES; DÍAZ; JURADO, 2012; TING; LIAO, 2013; WHITE; CENSLIVE, 2013).

\section{REDUCTION OF INVENTORY LEVELS}

The operation of scheduled collection with time window constraints (Milk Run) has in its core reduction of inventory (holding cost) and transportation costs in the supply chain (procurement parts - inbound freight and cost). If one company can reduce the procurement parts it is possible to reduce the work-in-process inventory (production) and in the finished goods inventory (HA; PARK; CHO, 2011; TING; LIAO, 2013; WHITE; CENSLIVE, 2013; RAHMAN; WU, 2011).

These changes have increased pressure on all actors of a typical supply chain. Manufactures, eager to maintain margins, look for potential improvements to 
DOI: 10.14807/ijmp.v7i3.434

share with their customers and for concessions from their suppliers. An ideal system looks for total system saving that benefit every chain member and the consumers (HA; PARK; CHO, 2011).

Inventory is one key area that one company must manage carefully. The company must continually try to balance the cost of carrying inventory with customer service and responsiveness. This is an area that a company can focus on their partnership to reduce their mutual costs as well as to address excellent customer service issues (WHITE; CENSLIVE, 2013).

Through the use of electronic data interchange (EDI), one company and their suppliers have the opportunity to reduce paperwork, increase access to tracking and stocking level data, conduct electronic ordering and invoicing, and streamline others areas. Electronic data interchange (EDI) is the electronic computer-to-computer transfer of standard business documents between organizations. EDI transmissions allow a document to be directly processed and acted upon by the receiving organization. Depending on the sophistication of the system, there may be no human intervention at the receiving end. EDI specifically replaces more traditional transmission of documents, such as mail, telephone, and even fax, and may go well beyond simple replacement, providing a great deal of additional information. To support time-based competition, organizations are increasingly using information technologies as a source of competitive advantage. Systems such as quick response $(Q R)$, just in time (JIT), and efficient consumer response (ECR) integrate a number of information-based technologies in an effort to reduce the cycle time of each kind of order (service, acquisition etc.), speed up responsiveness, and reduce supply chain inventory (HA; PARK; CHO, 2011; FUENTES; DÍAZ; JURADO, 2012; WIENGARTEN et al., 2013; TING; LIAO, 2013, YANG et al., 2013; WHITE; CENSLIVE, 2013; BENNET; KLUG, 2012).

All flows are the result of a final decision of the consumer or user who buys the product. The entire process depends on the information flow from the customer to the firm and to the firm's suppliers. Communication is an integral part of a logistics system because no product flows until information flows. One challenge is to communicate the power of forecasts to the supplier, although the forecasts will maximize the supplier's ability to plan for upcoming sales demands. The variability in 
the orders cycle requires a safety stock. Since holding safety stock costs money, managers will try to reduce or eliminate variability. Forecasting can be used to predict demand more accurately, resulting in less safety stock. The use of logistic carrier or transportation carrier that provides consistent on-time delivery will reduce lead-time variability (GUIMARÃES et al., 2014; ZOTTERI, 2013; SNOO; WEZEL; WORTMANN, 2011; FUENTES; DÍAZ; JURADO, 2012; WIENGARTEN et al., 2013; TING; LIAO, 2013; YANG et al., 2013; BENNET; KLUG, 2012; RAHMAN; WU, 2011).

An automated and integrated processing order system that utilizes updated customer demand data and is linked to forecasting and production schedule can reduce the time needed to perform certain elements of the orders cycle in processes and inventory replenishment. Inventory reductions have far-reaching implications on organizational return of investment (WHITE; CENSLIVE, 2013).

Transportation is one of the largest logistics costs and may account for a significant portion of the selling price of some products. Logistics Carriers can achieve sizable benefits by optimizing their routing and scheduling activities. In general, the benefits to a carrier when the routing process is improved include greater vehicle utilization, higher levels of customer service, reduction of transportation costs, reduced capital investment in equipment, and better management decision making (TING; LIAO, 2013; HÜBL; JODLBAUER; ALTENDORFER, 2013; RAHMAN; WU, 2011).

Intelligent inventory management planning may reduce the inventory levels and thereby the operational costs for storage/retrieval and order picking. Inventory reductions may be established by having smaller ordering quantities delivered more frequently. One company can reduce the need for storage space by carefully scheduling the deliveries (HÜBL; JODLBAUER; ALTENDORFER, 2013; LIAO; EGBELU; CHANG, 2013; WHITE; CENSLIVE, 2013).

There are three basic types of supply channels.

- Direct: the supplier delivers the materials directly to the manufacture site by one of the modal options.

- Assembly: the supplier delivers to an assembly point in relatively small volumes, where the material is combined with that of other vendors for direct shipment by one of the modal options to the manufacturing site. 
DOI: 10.14807/ijmp.v7i3.434

- Milk-Run: a logistic carrier sends a vehicle on a pre-selected route, stopping at each of several vendors to pick up material, and then delivering the total load to the manufacturing site.

Collecting is a way to consolidate freight that involves trucks picking up material from more than one supplier on each trip to a single destination. The main point is to simultaneously optimize vehicle routes and dispatch frequency in order to minimize transportation and inventory cost (GORMAN et. al., 2014; DEMIR; WOENSEL; KOK, 2014; TING; LIAO, 2013; WHITE; CENSLIVE, 2013; RAHMAN; WU, 2011).

Logistics strategic planning is a complex process that requires an understanding of how the different elements and activities of logistics interact in terms of trade-off and total cost to the organization. Only by understanding the corporate strategy, logistics can best formulate their own strategy. An important component in supply chain design and analysis is the establishment of appropriate performance measurement. A performance measurement, or set of measurement, is used to determine the efficiency of an existing system, or to compare with alternative systems. Performance measurements are also used to design proposed systems, by determining the values of the decision variables that yield the most desirable levels of performance (HA; PARK; CHO, 2011; TING; LIAO, 2013).

\section{THE MILK RUN SYSTEM}

Industrial Planning: the automaker logistics teams along with the logistics carrier define what will be the suppliers that will be part of the scheduled collection process and the need for routing collections (TING; LIAO, 2013).

Logistics carrier: Receives information from logistics teams of the plant and sets a transportation plan. It makes contact with suppliers, collects and manages transport, until the arrival at the assembly on scheduled time (BENNET; KLUG, 2012; RAHMAN; WU, 2011).

Supplier: Prepare for the collection of pieces based on the information received from logistics provider (specification and quantity of parts). It must respect the days and time pre-set for the collection of pieces. 
DOI: 10.14807/ijmp.v7i3.434

Reception of materials: The automaker will receive the collected pieces, distributing them in sequence on the production line. Thus, the company avoids wasting time in the process of unloading the vehicle that collected the pieces. The driver must load the vehicle in order to get the best layout to facilitate unloading in the automaker. The driver of the vehicle notifies the automaker when it is about ten minutes to the scheduled time for delivery. Thus, all the resources necessary to unload the vehicle will be prepared. The reception of the vehicle must be fast, differently from the normal patterns of a provider who is not engaged in this system (SNOO; WEZEL; WORTMANN, 2011; TING; LIAO, 2013).

Logistics of the automakers: The authorization of delivery is emitted electronically, based on the number of parts required to fill the production line. In order not to generate inventory in the logistics chain, it is important to work with the minimum required quantity of parts (SNOO; WEZEL; WORTMANN, 2011; TING; LIAO, 2013; WHITE; CENSLIVE, 2013).

\subsection{Advantages for the automakers}

Reduction in the unit cost of the part: The automaker collects at its suppliers only the parts in the required amount in days and pre-defined schedules. The planned quantity of pieces arrives at the automaker only when ordered.

Maximum utilization of vehicle: The same vehicle is used to collect several requests from several suppliers. The aim is that that vehicle has always the maximum utilization of its space, which means saving time and money (FUENTES; DÍAZ; JURADO, 2012).

More flexibility in receiving materials: Another good point of the scheduled collection system, Milk Run, is to reduce the flow of vehicles in the automaker. This ensures a more effective delivery, because the time that each vehicle will deliver the parts in the automaker is scheduled. Some devices are required for discharging, for example, a forklift. With the scheduled time to receive the parts, the automaker can schedule its equipment and human resources for that task (SNOO; WEZEL; WORTMANN, 2011; TING; LIAO, 2013).

Milk Run is teamwork, with activities coordinated by the Industrial Engineering sector. In the initial phase, the partnership with the purchasing sector must ensure the negotiation with the supplier. In the operational phase, logistics teams shall 
DOI: 10.14807/ijmp.v7i3.434

determine the schedule of consumption, ie, the frequency and quantity of parts ordered to meet the production line and perform the production planning scheduled for a certain period with the lowest stock (FUENTES; DÍAZ; JURADO, 2012; YANG et al., 2013).

The logistics carrier manages the operation as soon as the automaker defines what, when and how many to produce. At that stage, timetables for withdrawal of parts from suppliers on preset days are defined. As for the operational side, the logistics operator actions include:

Fulfilling the days and hours of collection; contacting suppliers to schedule the operation of collecting the pieces, setting how many vehicles will be required for each operation and checking the specifications of packaging (FUENTES; DÍAZ; JURADO, 2012).

\subsection{REQUIREMENTS TO IMPLEMENT MILK RUN SYSTEM}

Getting subsets assembled by suppliers or set of parts with shipping documents ready for shipment, so it does not exceed the determined window time for each provider within an established route for the vehicle.

Suppliers must not be distant from the plants. If they are distant, it is necessary to provide a place for consolidation of load before transportation.

The combined standardization of packaging among automaker, suppliers and logistics carrier is essential. If the automaker changes its packaging, it notifies the logistics carrier in advance in order to determine the best vehicle for the programmed collection of parts, since a change in packaging can affect the capacity of a vehicle, decreasing efficiency and thus, the process would not contribute to minimize transport costs in the integrated logistics chain. The supplier may also be informed in advance if the package is changed. Thus, the logistics carrier, or the third that performs the system to collection of parts, can deliver the new empty packaging to the suppliers in advance, benefiting the next scheduled collection (FUENTES; DÍAZ; JURADO, 2012; TING; LIAO, 2013).

The logistics carrier must comply with the time window for collecting the parts from suppliers and delivery them at the designated time to the automaker. Otherwise, it will affect costs, since the collected parts will not arrive at destination at the 
DOI: $10.14807 /$ ijmp.v7i3.434

programmed time and a stop on the automaker's assembly line may occur (SUN et al., 2014; SNOO; WEZEL; WORTMANN, 2011).

The automaker must inform the demand for parts, represented by the amount over a certain period (that period depends on the type of management of each automaker industry). It should also inform when those parts must enter the assembly line so that its suppliers can plan and schedule their production, with sufficient time to fulfill the production plan at the moment of collection. The logistics carrier need this information to plan the demand and program the collection of parts, in order to reach the lowest operating cost of transportation at Milk Run system, better leveraging the capacity of the transport vehicle (ZOTTERI, 2013; WIENGARTEN et al., 2013; BENNET; KLUG, 2012; RAHMAN; WU, 2011).

Suppliers must deliver parts in the amount scheduled by the automaker. If the amount of available pieces exceeds what was planned, the responsible for vehicle must not proceed with the collect, both for reasons of weight or volume, or not to affect the next collect in another supplier on its route. In case the quantity of parts provided by the supplier at the time of collection is lower than programmed, the logistics carrier must obtain an endorsement from the automaker.

Suppliers must deliver your parts within quality specifications stipulated by the automaker to avoid stop in production or extra transport, since the scheduled collect system aims at reducing inventory and costs in integrated logistics chain (IVER; SARANGA; SESHADRI, 2013).

The automaker, however, must have a very accurate knowledge of its demand, avoiding large fluctuations over the blanket orders collection pieces.

\section{ANALYTIC METHODS FOR CONVENTIONAL AND MILK RUN SYSTEM}

According to Figure 2, the Conventional system suppliers deliver their pieces or components to the automaker. In that system, the shipping costs are included in the price. That is, the automaker purchases CIF (cost insurance and freight). In Milk Run system, the automaker collects parts or components directly from suppliers. That is, the automaker purchases FOB (free on board). Transport costs therefore have to be paid by the automaker (VERGARA; ROOT, 2013; TING; LIAO, 2013). 


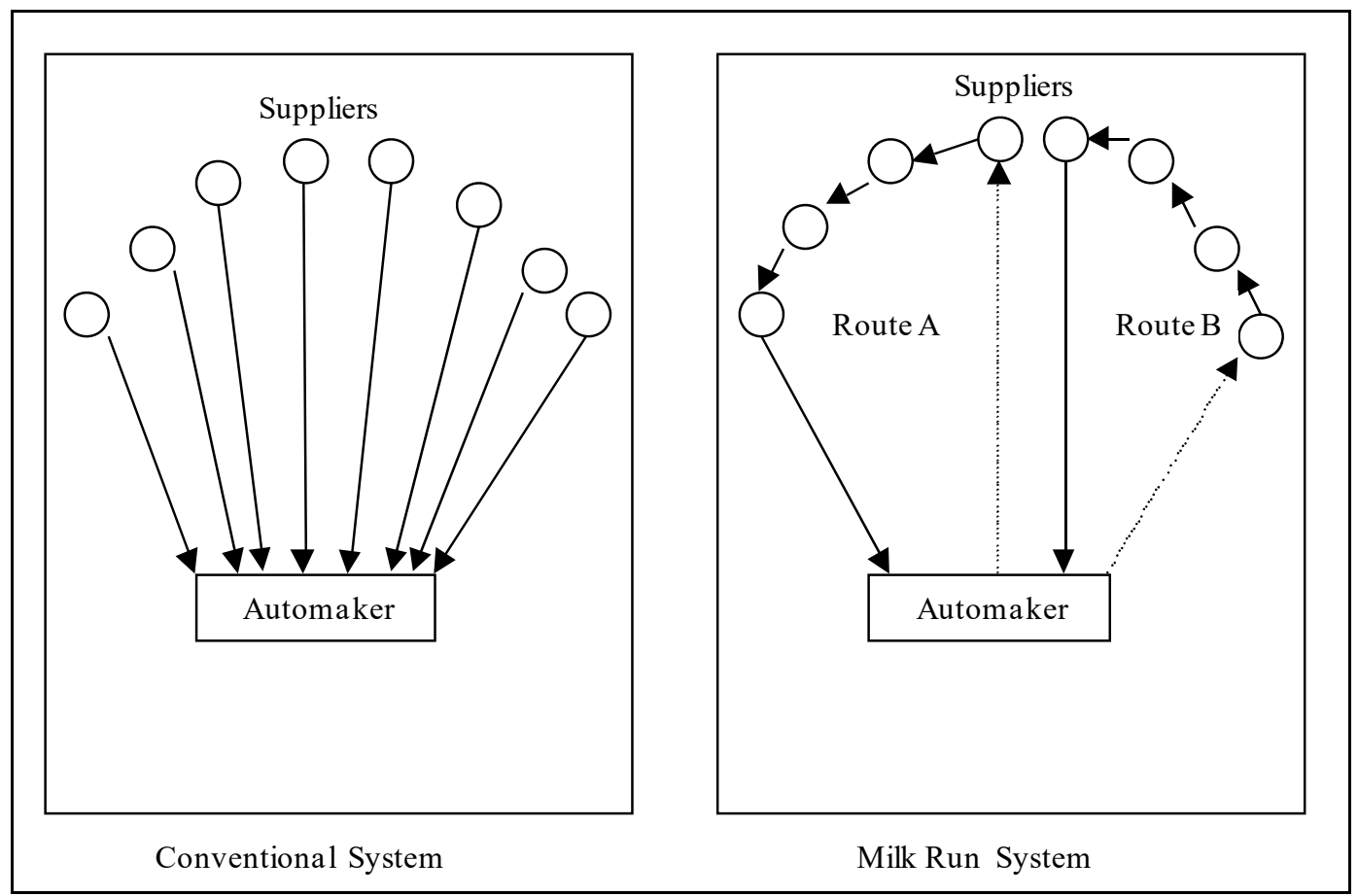

Figure 2: Conventional and Milk Run Systems

At the scheduled collection system, Milk Run, vehicles used to transport the parts should maximize capacity and optimize the route. The aim is to minimize the cost of transportation of the operation (GUIMARÃES et al., 2014; RAHMAN; WU, 2011).

With the Milk Run system, the parts will be transported to the automaker in the right amount and only when they are ordered. Thus, the assembler will no longer receive larger quantities than what has been programmed.

\subsection{1. CONVENTIONAL SYSTEM}

This system analyses the total costs (transportation and holding cost) of shipping loads from one supplier directly to the automotive plant. The equation is as it follows (DEMIR; WOENSEL; KOK, 2014; SUN et al., 2014; GUIMARÃES et al., 2014).

Considering a single customer the total cost is:

$$
C=C s+C i=\frac{\gamma+\sigma+\alpha D i s t}{Q}+C c I\left(\frac{Q}{d}+T\right)
$$

Let:

Cs $\quad=$ transportation cost per item;

$\mathrm{Ci} \quad=$ inventory cost per item; 
INDEPENDENT JOURNAL OF MANAGEMENT \& PRODUCTION (IJM\&P)

http://www.ijmp.jor.br

v. 7, n. 3, July - September 2016

ISSN: 2236-269X

DOI: 10.14807/ijmp.v7i3.434

$\gamma \quad=$ fixed cost of the truck (\$/day);

$\sigma \quad=$ fixed cost by collecting $(\$ /$ trip$) ;$

$\alpha \quad=$ transportation cost per unit distance $(\$ / \mathrm{km})$;

Dist = supplier to automotive plant trip distance $(\mathrm{km})$;

$\mathrm{Q} \quad$ = shipment size - economic order quantity - EOQ (items/load);

$\mathrm{Cc}=$ item value $(\$ /$ item $)$;

I = inventory carrying charge (\%/year);

$\mathrm{d} \quad=$ customer demand (items/week)

$\mathrm{T} \quad=$ supplier to customer transit time (weeks).

The inventory cost raises linearly with the batch size in the Conventional system. Thus, if the batch size increases there is a reduction at the transportation cost per item, but consequently increases the inventory cost. So, there is a first analysis of the trade-off, depending on shipment size (VERGARA; ROOT, 2013; TING; LIAO, 2013; RAHMAN; WU, 2011).

The analysis starts in the yearly demand for parts. Three different sizes of lots of supplies are adopted (Q1, Q2 and Q3). It is analyzed, first, the unit cost of purchase. A larger size of purchasing lot enables obtaining a discount on the unit price. For this reason, the unit cost is represented by Cunit1, Cunit2 and Cunit3, in Table 2, where Cunit1 <Cunit2 <Cunit3.

The shipping cost in the Conventional system is embedded in the price of the piece; it is the supplier who pays the costs managing the transaction until delivery at the automaker's plant. Therefore, if the lot size to purchase parts is larger, the unit cost of transport tends to decrease when it deals with the largest possible capacity of the vehicle (weight or volume) that will perform the transport of parts (SNOO; WEZEL; WORTMANN, 2011; TING; LIAO, 2013).

The cost of direct delivery (Conventional) per charge will be:

$$
\text { Ctvv }=\gamma+\alpha . \text { Dist }
$$

$\gamma=f(W b)$ 
DOI: 10.14807/ijmp.v7i3.434

$$
\alpha=f(W b)
$$

CtvV $=$ Total cost of vehicle by trip

$\gamma \quad=$ Fixed cost per day

$\alpha \quad=$ Cost per kilometre

$f \quad=$ function

$W b \quad=$ Vehicle gross capacity (weight and volume)

Dist $=$ Distance from supplier to cliente $(\mathrm{km})$

The unit cost of transport (of part or component) will be:

Cutr $=$ Ctvv $/ Q$

Thus, Cutr1 $<$ Cutr2 $<$ Cutr3 (unit cost of transport), because the larger the size of the lot, the lower unit cost of transportation, until the limit of the liquid capacity of the vehicle that will perform the operation (net capacity of the vehicle is equal to eighty five percent of the gross vehicle capacity in terms of weight or volume transported).

The number of supplies per period, which is a direct function of demand in the period and the acquisition batch size $(D$ and $Q)$, will decrease as it increases the acquisition batch size of parts, Nab1 $<$ NAB2 $<$ Nab3. The unit cost of order preparation $(\mathrm{Cp})$ in table 1 will not change because of the size of the purchase. However, the number of orders will change according to the acquisition batch size, thus influencing the total cost of order preparation.

The financial rate on stock or opportunity cost (I) will decrease due to the smaller acquisition batch size. If the acquisition batch size is large (Q1), there must be stocks in the automaker's plant and, consequently, the financial rate on stock (I) will be higher compared to the financial charge in a lower acquisition batch size (Q3). Thus, Table 1 shows the 11,12 and 13 where $11>12>13$ variables.

Finally, there is the variable average stock $(\mathrm{Qm})$ that is directly related to the acquisition batch size of parts. Therefore, if the acquisition batch size of parts $\left(Q_{n}\right)$ is large (Q1), there is likely to have stocks of parts in the automaker's plant. Thus, the average stock will depend directly on the acquisition batch size Qm1> QM2> QM3. 
INDEPENDENT JOURNAL OF MANAGEMENT \& PRODUCTION (IJM\&P)

http://www.ijmp.jor.br

v. 7, n. 3, July - September 2016

ISSN: 2236-269X

DOI: 10.14807/ijmp.v7i3.434

Table 1: List of Variables in the Analysis of Trade-offs

\begin{tabular}{l|c|c|c}
\hline \multicolumn{4}{c}{ Component "X” } \\
\hline Current Demand & D & D & D \\
\hline Size of Batch & Q1(Big) & Q2 (Medium) & Q3 (Small) \\
\hline Unit cost & Cunit1 & Cunit2 & Cunit3 \\
\hline Unit cost of transport & Cutr1 & Cutr2 & Cutr3 \\
\hline Number of supplies per period (D/Q) & Nab1 & Nab2 & Nab3 \\
\hline Unit cost of order preparation & Cp & Cp & Cp \\
\hline The financial rate on stock or opportunity cost & $I 1$ & $I 2$ & $I 3$ \\
\hline Average inventory & Qm1 & Qm2 & Qm3 \\
\hline
\end{tabular}

\section{2. $\quad$ COST OF ACQUISITION}

If the acquisition batch size is large (Q1) there will be a tendency to Caq1, cost of acquisition, ( $D$ Cunit1 $x$ ) to be less than Caq3, cost of acquisition, ( $D \times$ Cunit3) when the acquisition batch size is small (Q3), because there will likely be a larger discount on unit cost of purchase, depending on the acquisition batch size of parts (Q1>Q3, and therefore Cunit1 <Cunit3).

\subsection{COST OF ORDER PREPARATION}

If the acquisition batch size is large (Q1), the number of supply per period $(\mathrm{Nab})$, which involves the variables demand in the period and batch size $(D, Q)$, will be smaller (= Nab1 D/Q1). The unit cost of order preparation (Cp) does not change with the quantity purchased, the total order preparation cost (CPED), (Generic Costs Relating to Batch Size), will be smaller when the batch size is large, since in their formulation there is a relationship between demand in the period, batch size supply and the unit cost of preparing the application.

\subsection{INVENTORY MAINTENANCE COSTS}

If the acquisition batch size is large (Q1) the average stock (QM1) is larger than the average stock (QM3) when the batch size is smaller (Q3). As the cost of holding inventory (Ce), Costs Relating to Generic Batch Size, depends on the average inventory for the period $(\mathrm{Qm})$, unit cost of purchase (Cunit) and the rate financial charges on inventories or opportunity cost (I), it's conclude that, the smaller the size of the lot acquisition of parts $(Q)$, the lower the cost of maintaining inventory period $(\mathrm{Ce})$. 
DOI: 10.14807/ijmp.v7i3.434

If Q1> Q3 (batch size of supply), QM1 will be larger than QM3 (average stock), I1> I3 (financial charges on the stock) and only Cunit1 <Cunit2 (unit cost of purchase). Therefore, the reduction in the unit cost of purchase (Cunit) would have to be very advantageous to justify the average stock of parts.

\subsection{COST OF TRANSPORT}

If the acquisition batch size (Q1) is large the number of deliveries (NV) to the automaker's plant will be small compared to a smaller batch size (Q3). The total cost of the vehicle per trip (Ctvv) depend on the fixed and variable costs of the vehicle. Therefore, if the batch size is large, a vehicle with higher capacity will be necessary (in weight and volume) compared to a small acquisition batch size (Q3) for the system called Conventional. Thus, it would directly influence the total cost of the vehicle, as the fixed and variable costs of a vehicle with higher capacity are higher than the fixed and variable costs of a lower capacity vehicle (VERGARA; ROOT, 2013; TING; LIAO, 2013).

From the viewpoint of the conventional system, it is important for the supplier to supply the automaker with the largest batch possible, for thus it would minimize the costs of transportation or setup of machines in the production line, since this batch size does not exceed the net capacity of the transport vehicle (RAHMAN; WU, 2011).

\subsection{COLLECT SCHEDULING (MILK RUN)}

Kanban is used to manage the necessity of parts between automotive production plant and its suppliers. One logistic carrier or carrier sends a vehicle on a pre-selected route, stopping at each of several vendors to pick up material, and then delivers the total load to the automotive plant. The total transportation cost and inventory is presented as (ZHANG, 2013):

$$
C^{\prime}=C s^{\prime}+C i^{\prime}=\left(\frac{\alpha D i s t^{\prime}+N v \gamma}{W l p}\right)\left[\left(\frac{p c}{Q^{\prime}}\right)+p p\right]+C c I\left\{\frac{N Q^{\prime}}{d}+(T v+T d p)+\left[\frac{(m T c)}{2}\right]\right\}
$$

or

$$
C^{\prime}=C s^{\prime}+C i^{\prime}=\left(\frac{\alpha D i s t^{\prime}+N v \gamma}{W l v}\right)\left[\left(\frac{v c}{Q^{\prime}}\right)\right]+C c I\left\{\frac{N Q^{\prime}}{d}+(T v+T d p)+\left[\frac{(m T c)}{2}\right]\right\}
$$


Let:

Dist' = supplier to automotive plant distance - line haul, local and back haul $-(\mathrm{km})$;

$\mathrm{Nv} \quad$ = number of trips during one day (trips/day);

Wlp = net capacity of the truck (weight $-\mathrm{kg}$ );

$\mathrm{pc} \quad=$ weight of each container $(\mathrm{kg})$;

Q' = shipment size per container or Kanban cards (items/Kanban);

$\mathrm{pp} \quad=$ weight by part $(\mathrm{kg})$;

$\mathrm{N} \quad=$ total Kanban cards at each supplier (Kanban/supplier);

TV = trip time (line and back haul);

Tdp = unload time the parts in the automotive plant (hour);

$\mathrm{m} \quad=$ average number of customer stops per load;

Tc = average time of each collecting (hour);

WIV = net capacity of the truck (volume $\left.-\mathrm{m}^{3}\right)$;

$\mathrm{vc} \quad=$ container volume $\left(\right.$ volume $\left.-\mathrm{m}^{3}\right)$.

The equations 3 e 4 are similar, but equation 3 depends on the weight transported by the truck in the collecting schedule system (Milk Run) and equation number 4 depends on the volume transported by it. Thus, both equation 3 and 4 depend on the number of suppliers at each collecting route and on the weight and volume to be transported by each supplier (TING; LIAO, 2013).

\subsection{MILK RUN SYSTEM - SITUATIONS}

From the point of view of the Milk Run system, reducing the cost of storage would be the biggest gain since the company would supply its production with only the required parts, eliminating the variable stock in the automaker. The cost of transport would be minimized or perhaps slightly higher than the "conventional" system because the capacity of the transport vehicle was being maximized, regardless of who is performing the operation (logistics carrier, carrier or automaker with its own fleet). The number of orders increases in this system (Milk Run), since the Kanban technique is used, in which supplies (parts and components) are 
DOI: 10.14807/ijmp.v7i3.434

transported only in the amount determined by the Kanban although more frequently. However, the commitment between the parts (assembler and supplier) tends to increase, as well as the information flow, optimizing the process of ordering supplies which should reduce the administrative costs of receiving materials. Moreover, depending on the financial importance of the item to be ordered by the automaker (within ABC classification), collection of a component or part within the category "C" several times a week would not be justified, because the cost of invoice in each collection could be higher than keeping that item in stock for a few days (VERGARA; ROOT, 2013; WIENGARTEN et al., 2013; TING; LIAO, 2013; YANG et al., 2013; LIAO; EGBELU; CHANG, 2013; ZHANG, 2013; BENNET; KLUG, 2012).

The supply batch size of each component in Milk Run system depends on some variables. One is the time taken by the vehicle to run the complete programmed route of collection of parts. This time directly influences the formula of Kanban system, as shown in equation number 5 - Calculation of Quantity of Kanban Cards. Another variable that influences the size of the lot is the safety factor associated with the runtime of the collections and the daily demand for each part or component (ZHANG, 2013).

$$
N=\left[\frac{D}{Q} \times \operatorname{Tmov} \times(1+S)\right]
$$

Where:

$\mathrm{N}=$ total number of Kanban cards in the system.

$D=$ average daily demand of the item (items / day).

$\mathrm{Q}=$ batch size per container / packaging or card (items / card).

Tmov = Total time to a movement Kanban card complete a circuit, in percentage of the day, between the storage areas ("supermarkets") the producer and consumer (\%).

$S=$ Safety factor, in percentage of the day $(\%)$.

In the Milk Run system unit cost of purchase (Cunit) is lower compared to the conventional system, regardless of the quantity purchased. The automaker is responsible for shipping costs. Therefore, this cost should be eliminated from the unit purchase price. The number of pieces of each batch (containers / packaging) in Milk 
DOI: 10.14807/ijmp.v7i3.434

Run system is much lower when compared to the conventional system, although the frequency of supply is larger (SUN et al., 2014; TING; LIAO, 2013; LIAO; EGBELU; CHANG, 2013).

The average stock of parts in assembler and supplier is easily obtained when the maximum number of containers (number of Kanban cards) is defined. That quantity of containers per part (supplier) will be modified only if there is fluctuation in demand from the automotive market. In this case, it would be necessary to calculate the number of containers / packaging of each piece again (YANG et al., 2013; ZHANG, 2013).

The shipping cost in the Milk Run system is apportioned to the number of suppliers that each vehicle has on its route and the percentage by weight or volume in each collection. So there is a fixed cost of vehicle used on the route and a variable cost dependent on distance to be covered and the number of collections in a period (one work shift, for example).

The following formulas describe step by step the variables inherent to transportation and inventory costs of a product that will be used in both models, Milk Run and Conventional. The transport vehicle capacity (capacity of vehicle in weight and volume), with fixed and variable costs of the vehicle (total cost per trip), daily fixed cost of vehicle, variable cost of vehicle, annual stocking rate, total cost of batch, acquisition cost, transportation cost, and annual total cost of the system. It is presented in detail each item making up the final equation for both systems studied. Procedures of calculations performed in both systems (DEMIR; WOENSEL; KOK, 2014; SUN et al., 2014; GUIMARÃES et al., 2014; VERGARA; ROOT, 2013; TING; LIAO, 2013).

a) The company determines the acquisition batch size.

b) The batch size implies the following costs:

c) Unit cost: purchase price (Cunit)

d) Total Order Preparation Cost: $d=(D / Q) C p$, where:

$D=$ Annual Demand

$\mathrm{Q}=$ Batch size per order 
DOI: 10.14807/ijmp.v7i3.434

$\mathrm{Cp}=$ Order preparation cost

e) In-stock cost: $\mathrm{Ce}=\left(\mathrm{Qm}{ }^{*} \mathrm{Cunit}{ }^{*} I\right)$, where:

$Q m=$ Average batch size per order $-Q / 2$

$I=$ Annual stocking rate $(\%)$

f) Total cost of batch: $C T L=C p e d+C e$

g) Acquisition Cost: Caq $=D *$ Cunit

h) Partial total cost: CTP $=$ Cped $+\mathrm{Ce}+\mathrm{Caq}$

i) Transportation cost: Ctransp $=f(\mathrm{Nab}, Q, \mathrm{Pl}, \mathrm{VI}, \mathrm{W}, \mathrm{CtvV})$, onde:

$N a b=$ Number of supplies per order

$N a b=$ Demand $(D) /$ Supplying batch size $(Q)$

$P I=$ Batch wieght $(\mathrm{kg})$

$V I=$ Volume of supplying batch $\left(\mathrm{m}^{3}\right)$

$W=$ Capacity of vehicle in weight and volume

Ctvv $=$ Total Cost per trip: Ctvv $=$ Fixed Cost + variable cost

$C f=$ Daily Fixed cost of vehicle $(\$ /$ day $)$

$C V=$ Variable cost of vehicle $(\$ / K m)$

j) Annual Total cost of the system: CTSA $=$ CTP + Ctransp

k) Batch weight $(\mathrm{kg}): \mathrm{Pl}=\left(\mathrm{N}^{\circ}\right.$ package $\mathrm{x}$ package weight $)+($ batch size $\mathrm{x}$ part weight)

I) Batch Volume $\left(\mathrm{m}^{3}\right): \mathrm{VI}=\left(\mathrm{N}^{\circ}\right.$ package $\mathrm{x}$ package volume $)+($ batch size $\mathrm{x}$ part volume)

Procedures of calculations performed in the Milk Run system, step by step.

a) Total time - trip + collections (in hours) is composed by:

Number of collections per route - A

Average time for each collection (in minutes) - B

Average time of trip - C 
DOI: $10.14807 /$ ijmp.v7i3.434

Time to unload charge at automaker's plant (in hours) - D

Total Time of trip $(T T V)=(A \times B)+C+D$

b) Total time of parts available to production - TTPDP

Time to make parts available to production: TDPP

Total time of trip (in hours): TTV

$$
\text { TTPDP }=\text { TDPP }+ \text { TTV }
$$

c) Time of moviment card (\% day) - Tmov

Tmov $=$ TTPDP/DU

TTPDP = Total time of pieces available to production

$\mathrm{DU}=$ Workdays per year

d) Total number of movement Kanban cards - $\mathrm{N}$

Daily demand $(D)$

Batch size by container $(Q)$

Movement Kanban card time (\% dia) - Tmov

e) Total inventory of items in the automaker - ETM

Quantity of parts/packages - QPE

Number of Kanban cards in the automaker - NCM

f) Weight of Kanban container with parts ( $\mathrm{kg})$ - PCK

Package weight $(\mathrm{kg})-\mathrm{PE}$

Quantity of parts per package - QPE

Daily demand rate $-T d d$

Workdays per year - DU

Total stock of Items in the automaker's plant - ETM

$\mathrm{Ra}=\left(\mathrm{Tdd}{ }^{*} \mathrm{DU}\right) /(\mathrm{ETM} / 2)$

g) Average cover - CM (dias) 
ISSN: 2236-269X

DOI: 10.14807/ijmp.v7i3.434

Workdays per year $-D U$

Indicator of Annual turnover (Ra)

$\mathrm{CM}($ dias $)=\mathrm{DU} / \mathrm{Ra}$

h) Number of trips per year (to supply demand) - NVA

Annual Demand $(D)$

Number of containers per trip - NCTV

i) Annual Cost of orders - CPA

Number of containers to be transported by trip - NCTV

Batch size per container $(Q)$

Cost per Order (Cped)

Stock rate $(I)$

Unit cost (Cunit)

j) Average annual cost per point of collection - CTA

Number of trips per year (supply annual demand) - NVA

Transportation Cost rate per product in each trip - RCTPV

(Check cost apportionment on table 34)

$C T A=N V A * R C T P V$

k) Annual Total Cost of the system - CTSAmr

Annual demand $(D)$

Unit cost (Cunit)

Annual cost of orders (CPA)

Annual cost of inventory $(\mathrm{Ce})$

Average cost of annual transport per point of collection (CTA) 
INDEPENDENT JOURNAL OF MANAGEMENT \& PRODUCTION (IJM\&P)

http://www.ijmp.jor.br

v. 7, n. 3, July - September 2016

ISSN: 2236-269X

DOI: 10.14807/ijmp.v7i3.434

\section{CONVENTIONAL VS. MILK RUN SYSTEM}

One analysis of both systems, Conventional and Milk Run with annual demand variation between 13,200 items/year items until 264,000 items/year is showed in the Table 2 and Figure 3 comparing the total cost (transportation and holding costs). The methodology was used to vary the demand for a particular product and evaluate the relevant costs to the two systems under consideration. The demand for a product ranged from 13,200 to 264,000 units / year to supply the production of an automobile assembly plant, located in the ABC region, in São Paulo, Brazil.

Table 2: Trade-off between transportation + inventory costs and annual demand

\begin{tabular}{ccc}
\hline Annual demand (unit) & Milk Run $\left(\mathrm{Ci}^{\prime}+\mathrm{Cs}^{\prime}\right) \$$ & Conventional $(\mathrm{Ci}+\mathrm{Cs}) \$$ \\
\hline 0 & 0.00 & 0.00 \\
\hline 13,200 & $4,237.26$ & $26,828.58$ \\
\hline 26,400 & $10,179.72$ & $38,124.37$ \\
\hline 39,600 & $10,782.32$ & $46,538.76$ \\
\hline 52,800 & $15,509.39$ & $53,799.93$ \\
\hline 66,000 & $16,418.25$ & $60,113.42$ \\
\hline 79,200 & $19,665.70$ & $65,973.71$ \\
\hline 92,400 & $18,444.24$ & $71,167.87$ \\
\hline 105,600 & $19,204.93$ & $76,141.07$ \\
\hline 118,800 & $21,377.69$ & $80,772.76$ \\
\hline 132,000 & $23,889.39$ & $85,159.85$ \\
\hline 145,200 & $26,232.22$ & $89,375.63$ \\
\hline 158,400 & $28,928.01$ & $131,839.81$ \\
\hline 171,600 & $32,318.06$ & $137,491.55$ \\
\hline 184,800 & $30,593.61$ & $142,227.87$ \\
\hline 198,000 & $32,717.13$ & $147,619.45$ \\
\hline 211,200 & $33,979.99$ & $152,174.46$ \\
\hline 224,400 & $36,116.78$ & $156,941.74$ \\
\hline 237,600 & $38,150.99$ & $161,437.90$ \\
\hline 250,800 & $40,188.89$ & $166,194.84$ \\
\hline 264,000 & $42,423.59$ & $170,212.13$ \\
\hline
\end{tabular}


DOI: 10.14807/ijmp.v7i3.434

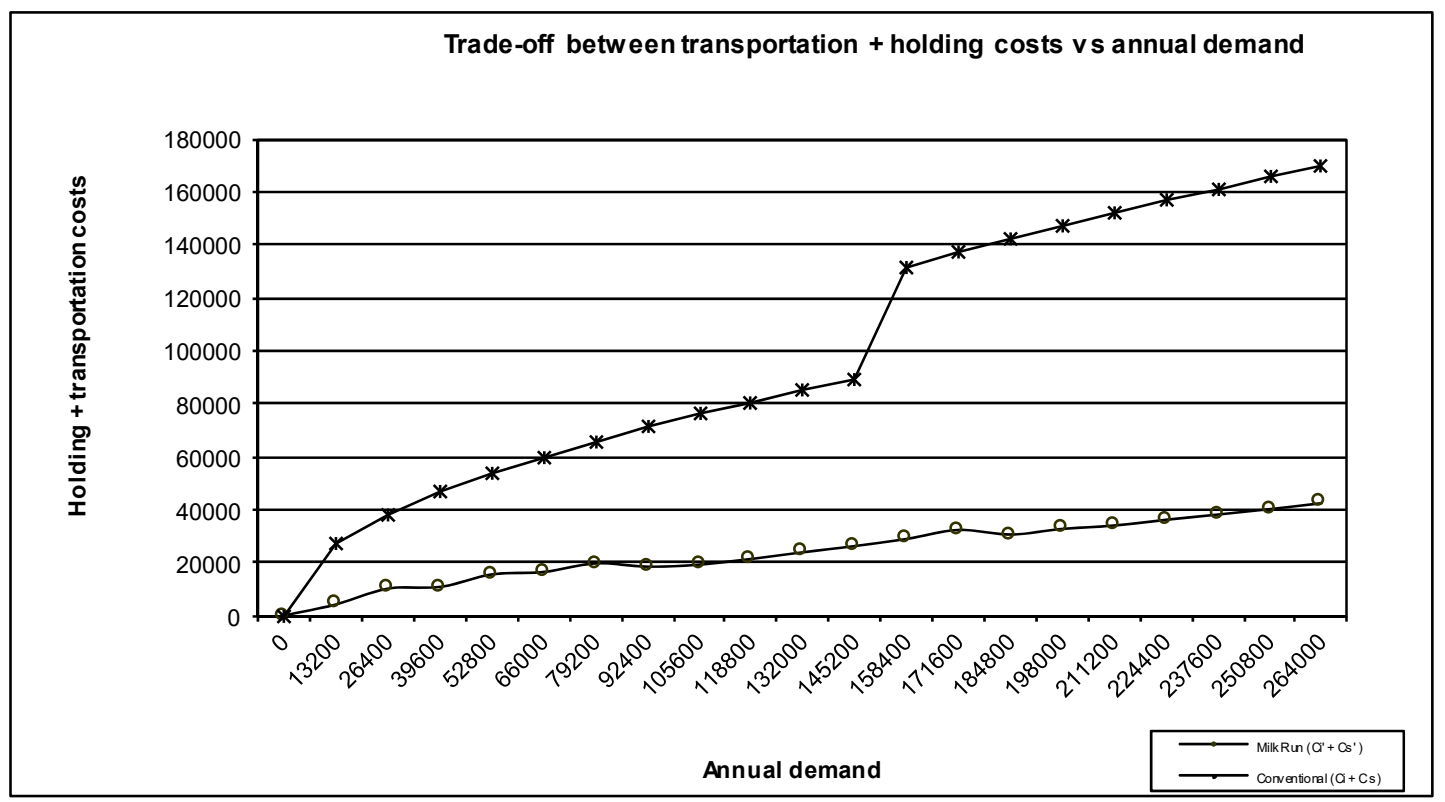

Figure 3: Trade-off

\section{CONCLUSIONS}

This paper showed the collecting schedule time window in the automotive companies in Brazil and their strategies to minimize the transportation and inventory costs in the supply chain management.

The analysis describes the importance of Milk Run to those automotive companies and one comparison of the Milk Run system to just-in-time system. Therefore, Milk Run is one initial approach to just-in-time philosophy.

When one company receives the parts directly from the supplier, it is necessary to increase the shipment size (batch) which consequently increases the inventory cost, too. The transportation costs per item can decrease, but it is not enough to overcome the inventory cost.

Through analytic method, equations for per-item transportation and inventory costs for direct supply and Milk Run supply were developed. At the Milk Run system, trucks have always to be delivered full.

Results indicate the Milk Run system is less expensive than conventional system (Table 2 and Figure 3). Since collecting allows frequent supplier shipments without excessive transportation costs (because trucks would always visit enough suppliers to be filled to capacity), it offers a way to minimize transportation costs when just-in-time production objectives are pursued. 


\section{REFERENCES}

BENNET, D.; KLUG, F. (2012) Logistics supplier integration in the automotive industry. International Journal of Operations \& Production Management, v. 32, n 11, p. 1281-1305.

DEMIR, E.; WOENSEL, T. V.; KOK, T. (2014) Multidepot distribution planning at logistics service provider Nabuurs B.V. Interfaces, v. 44, n. 6, November-December, p. 591-604.

FUENTES, J. M.; DÍAZ, M. S.; JURADO, P. J. M. (2012) Cooperation in the supply chain and lean production adoption evidence from the Spanish automotive industry. International Journal of Operations \& Production Management, v. 32, n. 9, p.1075-1096.

GORMAN, M. F.; CLARKE, J.P.; GHAREHGOZLI, A. H.; HEWITT, M.; KOSTER, R.; ROY, D. (2014) State of the practice: a review of the application of OR/MS in freight transportation. Interfaces, v. 44, n. 6, November-December, p. 535-554.

GUIMARÃES, L.; AMORIM, P.; SPERANDIO, F.; MOREIRA, F.; LOBO, B. A. (2014) Annual distribution budget in the beverage industry: a case study. Interfaces, v. 44, n. 6, November-December, p. 605-626.

HA, B-C.; PARK, Y-K.; CHO, S. (2011) Suppliers' affective trust and trust in competency in buyers its effect on collaboration and logistics efficiency. International Journal of Operations \& Production Management, v. 31, n. 1, p.5677.

HÜBL, A.; JODLBAUER, H.; ALTENDORFER, K. (2013) Influence of dispatching rules on average production lead time for multi-stage production systems. International Journal of Production Economics, 144, p. 479-484.

IVER, A.; SARANGA, H.; SESHADRI, S. (2013) Effect of quality management systems and total quality management on productivity before and after: empirical evidence from the Indian auto component industry. Production and Operations Management, v. 22, n. 2, p. 283-301.

LIAO, T. W.; EGBELU, P. J.; CHANG, P. C. (2013) Simultaneous dock assignment and sequencing of inbound trucks under a fixed outbound truck schedule in multidoor cross docking operations. . International Journal of Production Economics, 141, p. 212-229.

RAHMAN, S.; WU. Y-G F. (2011) Logistics outsourcing in China: the manufacturercum-supplier perspective. Supply Chain Management: An International Journal, v. 16, n. 6, p. $462-473$.

SNOO, C.; WEZEL, W. V.; WORTMANN, J. C. (2011) Does location matter for a scheduling department? a longitudinal case study on the effects of relocating the schedulers. International Journal of Operations \& Production Management, v. 31, n. 12, p.1332-1358.

SUN, X.; GARG, M.; BALAPORIA, Z.; BAILEY, K.; GIFFORD, T. (2014) Optimizing transportation by inventory routing and workload balancing: optimizing daily dray 
operations across an intermodal freight network. Interfaces, v. 44, n. 6, NovemberDecember, p. 579-590.

TING, C-K.; LIAO, X-L. (2013) The selective pickup and delivery problem: formulation and a memetic algorithm. International Journal of Production Economics, 141, p. 199-211.

VERGARA, H. A.; ROOT, S. (2013) Mixed fleet dispatching in truckload relay network design optimization. Transportation Research Part E, 54, p. 32-49.

WANG, H-F.; CHEN, Y-T. A. (2013) A coevolutionary algorithm for the flexible delivery and pickup problem with time Windows. International Journal of Production Economics, 141, p. 4-13.

WHITE, A. S.; CENSLIVE, M. (2013) An alternative state-space representation for APVIOBPCS inventory systems. Journal of Manufacturing Technology Management, v. 24, n. 4, p. 588-614.

WIENGARTEN, F.; HUMPHREYS, P.; McKITTRICK, A.; FYNES, B. (2013) Investigating the impact of e-business applications on supply chain collaboration in the German automotive industry. International Journal of Operations \& Production Management, v. 33, n. 1, p.25-48.

YANG, G.; DEKKER, R.; GABOR, A. F.; AXSÄTER, S. (2013) Service parts inventory control with lateral transshipment and pipeline stock flexibility. International Journal of Production Economics, 142, p. 278-289.

ZHANG, L. (2013) Kanban-controlled exponential production lines: analysis and design. Journal of Manufacturing Technology Management, v. 24, n. 3, p. 358383.

ZOTTERI, G. (2013) An empirical investigation on causes and effects of the bullwhipeffect: evidence from the personal care sector. International Journal of Production Economics, 143, p. 489-498. 